\title{
Learning within a Supportive Environment: Mentoring Skills
}

\author{
Lyn McDonald \\ Faculty of Education and Social Work, University of Auckland \\ PB 92019, Auckland 1142, New Zealand \\ Tel: 096238899 ext. 48710 E-mail: 1.mcdonald@auckland@auckland.ac.nz \\ Annaline Flint \\ Faculty of Education and Social Work, University of Auckland \\ PB 92019, Auckland 1142, New Zealand \\ Tel: 096238899 ext. $48710 \quad$ E-mail: a.flint@auckland.ac.nz
}

Received: August 4, 2015 Accepted: August 17, 2015 Published: September 23, 2015

doi:10.5296/jet.v3i1.8095 URL: http://dx.doi.org/10.5296/jet.v3i1.8095

\begin{abstract}
New teachers moving into teaching need the critical support that teacher induction programmes provide them with. The purpose of this paper is to discuss the specific skills and particular knowledge mentor teachers require in supporting provisionally registered teachers' (PRTs) learning. Data for this qualitative study were gathered from 17 mentor teachers using semi-structured individual interviews which were audio-taped, transcribed and analysed using a thematic approach. In this paper it will be argued that the role of the mentor teacher is an important and significant one for PRTs. Findings from the study showed that there are specific skills and knowledge required by mentor teachers for effective mentoring with PRTs. These skills include the ability to communicate clearly and have personal skills of supportiveness and understanding of the PRTs' learning. It is also necessary for mentor teachers to be reflective practitioners with knowledge of the curriculum and pedagogy. The findings have important implications for professional development, and practice in induction and mentoring programs.
\end{abstract}

Keywords: PRTs (Provisionally registered teachers), NZTC (New Zealand Teachers Council), mentor teachers, mentoring, professional development, beginning teachers

\section{Introduction}

When provisionally registered teachers (PRTs - teachers in their first or second year of teaching) in New Zealand were surveyed about their mentoring experiences, most participants reported that the level of mentoring, support, and assessment to which they were 
entitled (Cameron, Dingle, \& Brooking, 2007), was not being received or varied widely. The teachers felt that the lack of this structural support made them feel that they were expected to work independently, and seek out assistance from other teachers within their schools. It was further contended that PRTs should have access to the knowledge and thinking of their more expert colleagues within an integrated professional culture. Research (e.g., Cameron et al., 2007) suggests that all involved agencies and individuals in initial teacher education should develop comprehensive and aligned approaches to teacher induction programs in order to create more support for provisionally registered teachers. In New Zealand, teacher induction programs in primary and intermediate schools are provided with national guidelines and a staffing entitlement. These guidelines aim to facilitate on-site mentoring for PRTs in their first two years of practice, providing them and their mentors with release time used by individual schools as they see fit (NZTC, 2011).

It is a challenge in many countries, including New Zealand, to retain experienced teachers (Organization for Economic Co-operation and Development (OECD), 2005). When one considers the tremendous progress most PRTs make during their first two years in the classroom, then addressing the issue of a shortage of high-quality teachers is more about keeping the teachers the schools have, than it is about recruitment (Olesen, 2000). PRTs encounter issues relating to teaching and learning that are no different to those of their more experienced colleagues (Feiman-Nemser, 2003). However, despite intensive initial teacher education preparation for teaching, "beginning teachers have legitimate learning needs that cannot be grasped in advance or outside the contexts of teaching" (Feiman-Nemser, 2003, p. 26), thus reinforcing further the importance of effective mentoring.

Over the past two decades it has been recognized and acknowledged that the difficulties encountered by provisionally registered teachers, and their transition to teaching can be assisted and supported by workplace mentoring as a supportive strategy ( Hobson, Ashby, Malderez \& Tomlinson, 2009). The notion and value of learning communities within schools has been widely documented (Bullough, 1996), and teachers who have access to more enriched professional roles and collegial support felt more positive about the profession (Darling- Hammond, 1996). Like other teachers, PRTs would feel more effective and more able to focus if they were learning within supportive environments, thus reinforcing the importance and relevance of effective induction programs and professional development. It has been shown that emotional support is important for boosting the confidence of PRTs, enabling them to put difficult experiences into perspective, thereby increasing their morale and job satisfaction. Hobson et al., (2009) suggested that the most commonly stated benefits of effective mentoring in fact relate to the provision of emotional and psychological support. Further, findings by Hargreaves and Fullan (2000) also confirmed that emotional support is one of the strongest needs of PRTs, and that it is sometimes too easy to lose sight of the emotional dimensions of teaching.

\subsection{An Effective Induction Process}

An effective induction process is identified as a system for learning that occurs in a particular phase of a teacher's career (Britton, Paine, Pimm, \& Raizen, 2003; Cameron, 2007) and one 
which is essential in retaining and supporting new teachers. Induction is more likely to be effective where national, regional or state policies and resources enable the delivery of a coordinated system over time (Darling-Hammond, Berry, Haselkorn, \& Fidler, 1999). All effective induction programs, as suggested by Darling-Hammond et al., (1999) should incorporate three basic characteristics which include being comprehensive (i.e., an organization or structure that consists of many activities and where many people are involved); being coherent (i.e., the various activities and people involved are logically connected to each other) and being sustainable (i.e., the comprehensive and coherent program continues for many years). Comprehensive, sustained and coherent induction programs as described above will most likely demonstrate improved teaching (Portner, 2005).

For the successful induction of PRTs to take place in the first two years of teaching, it is also important that other teachers within the schools are involved and supportive. It is during this period of time "the collective professional community is charged with providing a range of intellectual, social, emotional and material resources" and should be supporting and guiding PRTs into the school environment (Ingersoll \& Kralik, 2004, as cited in Anthony, Haigh \& Kane, 2011, p.861). Norman and Feiman-Nemser (2005) also described this integrated professional culture within a school as one which explicitly values teachers' professional growth. Similarly, the seminal work of Kardos, Moore-Johnson, Peske, Kauffman and Liu (2001) proposed that when an integrated school culture of both veteran and beginning teachers model the school philosophy with PRTs, the beginning teachers are more likely to become part of the school's professional community of learners.

Over the past ten years, PRT mentoring in teaching has evolved. There has been a shift in emphasis, from short-term practical advice and emotional support to a process with the potential to strengthen teaching throughout a teaching career (Cameron, 2007). The mentoring of PRTs demands a vision of good teaching and a regard for them as learners, leading to a more principled approach, in the long term. One way of mentoring, educative mentoring, can be distinguished from other forms of mentoring (primarily about technical advice and emotional support) in that it responds to the current needs of the teacher, supporting them in their own learning progress (Norman \& Feiman-Nemser, 2005). Educative mentoring is therefore based on experiences that promote future growth and lead to richer subsequent experiences (Feiman-Nemser, 2001). It can also be argued that educative mentoring rests on an unequivocal vision of good teaching, and that mentors who share this vision address beginning teachers' concerns and questions about their teaching and progress (Feiman-Nemser, 2001).

\subsection{The Skills of an Effective Mentor}

Successful educative mentoring is dependent on the mentor having a clear understanding of what excellent teaching and learning entails. The New Zealand Teachers' Council Guidelines for Induction and Mentoring and Mentor Teachers (NZTC, 2011) defines a high quality mentor as a colleague who is experienced, skilled and trained to guide, support, give feedback to and facilitate evidence informed reflective learning conversations with the PRT. While not neglecting the emotional support needed to make a new teacher feel at ease, such a mentor would focus largely on providing the professional support needed by the teacher and 
progressing their understanding of teaching and learning (Little, 1990, as cited in Feiman-Nemser, 2001). Educative mentoring, as explained by Feiman-Nemser (2001), advances the development of new teachers by "cultivating a disposition of inquiry, focusing attention on student thinking and understanding, and fostering disciplined talk about problems of practice" (p. 28).

In order to acquire the appropriate skills and knowledge to be a mentor teacher it is important that professional development is offered within schools or clusters of schools. Professional development is an effort to bring about change in classroom practices of teachers in both their skills and beliefs (Guskey, 2002). Similarly Timperley (2008) commented that as teachers discover new professional knowledge and put into practice what they have learned, they begin to feel more effective as teachers. Mentor teachers need specific skills and knowledge in working with PRTs and these factors form the basis of the conceptual framework of this study. By skills the researchers are referring to abilities, proficiencies, skillfulness and competences the mentor teacher requires in their mentoring of PRTs. By knowledge the researchers are referring to the curriculum, content and pedagogical content knowledge it is necessary mentor teachers demonstrate in their mentoring practice.

\section{Background and Context}

The study this paper is based on was conducted within a New Zealand primary and intermediate mentoring and induction pilot, one of four induction and mentoring pilots funded by the New Zealand Teachers Council (NZTC). All the pilots aimed to explore a range of models for mentor teacher development and support, and to trial the Draft Guidelines for Induction and Mentoring and Mentor Teacher Development in Aotearoa New Zealand (NZTC, 2009). The pilots were carried out in a variety of school settings and with a range of models for high quality mentoring and induction programs. For the purposes of this paper six purposively selected state schools were selected because of their geographical location and close proximity to each other, making it more practical for the mentor teachers to attend professional development sessions at a central location. Principals, mentor teachers, PRTs and other staff from each school were included and invited to participate in the pilot project. The 17 participants (identified hereafter with pseudonyms) in this particular paper were the mentor teachers from the six selected schools.

\section{Methodology}

The research for this paper was located within the interpretive paradigm and used a qualitative approach. An interpretive paradigm enabled the complexities and practices associated with the mentoring skills of teachers to be explored and investigated in depth. One goal of the qualitative approach is to elicit understanding and meaning from the participants with the researcher being the primary instrument of data collection. Inductive strategies and analysis are also features of the qualitative approach with field work involved and the resulting data being richly descriptive (Merriam, 1998). The epistemological assumption of a qualitative approach is based on minimizing the distance between the researcher and the participants (Lincoln \& Guba, 2000). As researchers, we were involved in the research process, gaining rich description through understanding and interpreting the perceptions and 
viewpoints of all participants.

Qualitative data were collected from each of the 17 mentor teachers in the form of 45 minute semi-structured one-to-one interviews conducted during the first year of the project. The interviews were audio-taped, transcribed and analysed using a thematic approach, while the participants' voices are presented through direct quotes in italics. Appropriate ethical processes, approved by the ethics committee were followed which ensured that all participants in the study gave informed consent. The mentor teachers' ages ranged from 28-50 years, with teaching and mentoring experience from three to twenty years. The mentor teachers taught at a variety of teaching levels from years 1-8.

The thematic approach was chosen over other methods, because, as researchers we wanted to make sense of the data as it were collected, read, re-read and coded into manageable themes in relation to the research questions. The themes arose from a coding system which included open coding at the first level of conceptual analysis of the data, followed by axial coding where the relationship between the categories or themes was identified. Finally selective coding was used to identify and look back over the data and findings (Braun \& Clarke, 2006).

The research question which guided the analysis of the data was:

What role does the mentor teacher play in supporting provisionally registered teachers in their learning to be a fully registered teacher?

Two key themes emerged from the study. These were: demonstrating skills of communication and being supportive, and being a reflective practitioner with knowledge of the curriculum and pedagogy.

\section{Findings}

A high quality mentoring programme is one which provides a PRT with an experienced mentor who has the skill of being able to communicate clearly with them, and the ability to give feedback on their teaching and learning progress through effective learning conversations. A mentoring programme provides the mentor teacher with mentoring skills and the disposition to advocate on behalf of their PRT (NZTC Guidelines, 2011). Some of the mentoring skills included in professional development for mentor teachers are: developing greater confidence in the use of strategies such as goal setting, observations and professional learning conversations; developing a more critical approach and using evidence to reflect on their own mentoring practice; and clarity about the expectations around their mentoring role (NZTC Guidelines, 2011, p.49).

\subsection{Demonstrating Skills of Communication and Being Supportive}

The qualities two of the mentor teachers mentioned specifically, which they believed necessary were, “...being trustworthy, compassionate, friendly, empathetic and reassuring "(M.T.1; M.T.3). They further believed that the quality of the relationship between the mentor teacher and PRT served to enhance the learning for both parties. 
In the study the themes of being a good communicator, a support person and having understanding of PRTs and their teaching and learning progress were recognised and reiterated by the mentor teachers multiple times. Two mentor teachers acknowledged that at times they believed they lacked the necessary communication skills needed for successful mentoring and had worked hard to improve this skill. One mentor talked about having learnt the skill of communication through professional development explaining, "Good communication skills are so important because sometimes you have to give hard messages about learning progress to PRTs and this skill is not always easy " (M.T.1) while another mentor explained "...you need very good communication skills, that's probably the number one skill” (M.T.2).

The comments by the two mentor teachers indicate there is a need for effective, clear communication skills, such as active listening and at times asking critical, difficult questions of PRTs. Therefore there is a necessity for these specific skills of communication to be taught to mentor teachers through professional development. The importance of establishing relationships that allow for effective and honest communication was reiterated by another mentor who stated, "... we need to know how to create relationships that allow for effective communication, that allow for you to ask those hard questions" (M.T.4) supporting further what M.T.1 had expressed.

The skills mentioned in interviews multiple times by mentor teachers related to communication and support and the ability to listen without interruption during conversations with the PRT. The ability to provide honest, pertinent feedback about PRTs' teaching practice was also a necessary skill. All the mentor teachers $(n=17)$ remarked on the importance of having that honest communication at all times with their PRTs as well as good listening skills. They observed it was not only about listening but being able to give relevant feedback to the PRTs about their teaching. These particular findings support the NZTC Guidelines (2011) which states that the role of the mentor teacher includes listening to and helping the PRT to solve problems.

The ability of mentor teachers to listen to and help solve issues in relation to teaching and learning is an essential part of the mentoring process and therefore a skill a mentor should have and be able to utilise effectively. As another mentor teacher explained, "I think communication skills are very, very important and being able to read people somehow. Quite often it's not what they say but it's their gestures and things that you get the message through ....." (M.T.3).

Personal professional qualities such as being supportive, empathetic and approachable rated highly with three of the mentor teachers interviewed. This factor linked to the emotional support provided for PRTs which is an important part of the mentoring process. A particular point MT5 alluded to was, "Mentors need to be someone who can have that open door that they can go in and have a quick word with the PRT". While M.T.1 stated, "You need to be professional yet kind, professional yet friendly, professional yet understanding. And being empathetic but not to the point where you let it get in the way of what you are saying". 
Furthermore M.T.6 believed, "I always think the best way I can put it in some respects is you need to lead but also need to walk alongside someone in their journey to becoming a fully registered teacher. It is about learning together".

\subsection{Being a Reflective Practitioner with Knowledge of the Curriculum and Pedagogy}

Mentor teachers acknowledged in their interviews that it was vital for them to know about learners and learning in relation to pedagogy and curriculum and what is relevant to the PRT's teaching. That knowledge and understanding of education and content knowledge, knowledge of different learning approaches and a depth of knowledge about learners and learning was fundamental to their mentoring if they were to guide PRTs effectively. As M.T.7 commented, "Mentor teachers need to know about current theories of practice, current theories of teaching and resourcing and know how it all fits together. You need to know about children's development socially and cognitively".

The mentor teachers $(\mathrm{n}=17)$ interviewed agreed that having knowledge of their own teaching practice and being able to reflect and improve upon their practice was a significant part of being a mentor teacher. They stated that examples of techniques that assisted them in this process of critical reflection were classroom teaching experience, excellent classroom management skills and being secure in their own teaching practice. As one mentor teacher described in her interview:

Mentor teachers need to have been successful, they need to have a proven success rate in teaching and need to be up to date with teaching methods......They need to be an enquiring teacher really, because they're not going to be a very good mentor teacher if they're not enquiring enough and reflective, they need to have reflective skills and encourage that thinking in an outgoing way (M.T.7).

The mentor teachers explained the ability to reflect as being able to focus on inquiry into their own and others' professional practice and learning, based on a clear understanding of the features of excellent teaching. It also included the ability to demonstrate and explain to their PRTs this excellence in teaching practice. As M.T.1 explained:

What is important is being open to not only reflecting on your own practice but being open to questioning of your practice whether it's from yourself or your PRT or from someone else....knowledge of your own practice and being able to reflect on and improve your own skills is what is vital for a mentor teacher and that links into skills as well. If you can't reflect to improve on your own practice then how can you help another teacher?

For M.T.7 it was about having an excellent professional relationship with her PRTs and having empathy and compassion for teachers at the beginning of their teaching career and to clearly understand what acquiring a lot of knowledge in different curriculum areas entails.

It was clear also from the interviews that the mentors were aware of the importance and necessity of excellent and up- to- date curriculum knowledge and pedagogy and being able to reflect on this knowledge with their PRTs. For the mentors this meant they believed it was not only important to have that knowledge but they were able to apply that knowledge in 
classroom practice and be able to discuss it with their PRTs. As M.T.7 observed:

You need to have a good knowledge of the curriculum, planning, assessment and in order to reflect with your PRTs and you need to have a good knowledge of what it's like to be a PRT as well in your beginning years of teaching.

\section{Discussion}

Effective mentoring is an important part of the journey in teaching for PRTs in their first years of teaching. Much of the success of first and second year teacher progress is aligned with quality mentoring experiences that promote positive professional identity, resilience and the belief that their efforts as teachers make a difference (He, 2009). This paper focussed on the skills mentor teachers believed they should have in establishing and maintaining effective relationships with PRTs in their schools. The mentor teachers indicated in their interviews that as well as having specific skills relevant to mentoring, it was important to have a sound knowledge of curriculum and pedagogy which they were then clearly able to explain, discuss and reflect on with their PRTs.

It was also essential, they further commented, that mentor teachers were able to model and apply this knowledge effectively in the classroom for the PRTs. As Ball (2000) suggested, the link between strong curriculum knowledge and personal pedagogy is seen as a necessary attribute for PRTs to observe in their mentor teachers, as it provides them with sound foundations for their own thinking in relation to their teaching and learning progress. This particular knowledge and relevance of curriculum and pedagogy explained in the findings was also noted by $\mathrm{He}$ (2009) who stated, "proper content knowledge, pedagogical knowledge and content pedagogical knowledge" (p. 273) was important for PRTs and their learning as was the knowledge that their efforts as teachers make a difference. Rich pedagogical knowledge in mentoring also includes the ability to talk with PRTs about teaching in ways that connect between theory, practice and the school context PRTs work in (Feiman-Nemser \& Folden, 1986).

A shift in focus in teachers' professional development has moved the focus away from 'individual effort' to 'communities of learners' where newly qualified PRTs are nourished intellectually by engaging in collaborative practice (Thomas, Wineburg, Grossman, Hyhre, \& Woolworth, 1998). Mentors in the research study commented that building a relationship with PRTs and having a clear communication style with effective listening skills, was the foundation for all their work. In educative mentoring, the learning of the mentors and PRTs occurs through meaningful social communication, interaction and practice (He, 2009). This process involves being able to communicate ideas about teaching and learning with clarity and to acknowledge any concerns. This strength-based approach is closely aligned with educative mentoring in which both mentors and mentees are engaged in continued professional growth (Feiman-Nemser, 2001).

Mentors in the research study were reflective and clear about the processes involved in building relationships with the PRTs, and the importance of their role in this process. In the NZTC Guidelines (2011) part of the process of becoming a fully registered teacher is that PRTs should have access to effective and reflective mentor teachers who listen to and help 
them solve problems. Lopez-Real and Kwan (2005) related to the importance of mentors' learning through self-reflection or critical reflection on their own practice while Mulholland and Wallace (2001) noted that the development of a teacher's sense of efficacy has a powerful influence in their induction years. Therefore, these early years of teaching are decisive in the development of a teacher, and having mentor teachers who reflect in a critical and supportive manner with PRTs is essential. Evident also in the research (e.g., Lopez-Real \& Kwan, 2005; Mulholland \&Wallace, 2001) was the constructive effect mentoring and self-reflection had on the mentors themselves in their teaching practice.

Effective mentoring is about both retaining PRTs as teachers in the future and establishing and building upon strong foundations for quality teaching (Cochran-Smith, 2004). Darling-Hammond (1996) argued that teachers who have this access to teacher networks and enriched professional roles feel more optimistic about the profession, and as a consequence schools which encourage collaborative practice are more effective in assisting PRTs to develop their teaching practice. Cooper and Stewart (2009) commented, with this collaborative effort there is a provision to create richer learning experiences for all teachers and higher quality educational outcomes for students and their learning. An effective educative mentoring programme is part of an interactive working environment where, as research has indicated (Hicks, 1997), PRTs feel more positive about being teachers and more able to meet and improve students' learning. Mentor teachers should form close, supportive working relationships with their PRTs and relationships established on a foundation of respect, trust, understanding and support as was apparent in the research study.

The importance of professional discussions and sharing of ideas was highlighted by the mentor teachers as being crucial in their communication with their PRTs. Mentor teachers communicating in a clear and concise manner and giving relevant feedback is something which should be given more emphasis. For mentor teachers this emphasis means they have to establish a professional and open to learning relationship with the PRT, challenging their ideas and encouraging and supporting risk taking. Hargreaves and Fullan (2000) argued that emotional support is one of the strongest learning needs of PRTs. Evidence suggests that establishing that kind of rapport and offering emotional support are typically prerequisites to changing teaching practices (Zachary, 2000). Mentors' modelling and interactions with their mentees are vital for instilling the resilience necessary for teachers to meet the challenges they face in the future (He, 2009). It is about cultivating and creating a professional, open relationship between mentor and PRT which involves collaboration in learning experiences and facilitates personal, professional development.

\section{Final Considerations}

Some limitations to the current study need to be noted. The participants were not anonymous to the researchers because of the work they did within the project together. While this study was from one stakeholder's perspective (the mentor teacher), further research is required from the other stakeholder's perspective (the PRT), to confirm their viewpoint on effective mentoring skills. 
The benefits of the study on the field of practice (mentoring) are indicated below. PRTs need mentor teachers who have excellent qualities in mentoring such as a clear, responsive communication style and the ability to be effective, reflective practitioners themselves. These qualities should be linked with sound pedagogical and curriculum knowledge which they can model with their PRTs. The challenge then for mentor teachers is to improve the particular skills and knowledge required of mentors. Through in-depth professional development mentor teachers can build on existing expertise and secondly enable educative mentoring to become embedded in their practice.

\section{References}

Anthony, G., Haigh, M., \& Kane, R. (2011). The power of the 'object' to influence teacher induction outcomes. Teaching and Teacher Education, 27, 861-870 http://dx.doi:10.1016/ j.tate.2011.01.010

Ball, D. (2000). Bridging practices: intertwining content and pedagogy in teaching and learning to teach. Journal of Teacher Education, 51(3), 241-247.

Braun, V., \& Clarke, V. (2006). Using thematic analysis in psychology. Qualitative Research in Psychology, 3(2), 77-101. http://dx.doi.10.1191/1478088706

Britton, E., Paine, L., Pimm, D., \& Raizen, S. (2003). Comprehensive teacher induction Dordrecht: Kluwer Academic Publishers.

Bullough, R. V. (1996). Narrative reasoning and teacher development: A longitudinal study. Curriculum Inquiry, 26(4), 385-415.

Cameron, M. (2007). Learning to teach: A literature review of induction theory and practice.Wellington: New Zealand Council for Educational Research.

Cameron, M., Dingle, R., \& Brooking, K. (2007). Learning to teach: A survey of provisionally registered teachers in Aotearoa New Zealand. Wellington: New Zealand Teachers Council.

Cochran-Smith, M. (2004). Stayers, leavers, lovers and dreamers: Insights about teacher retention. Journal of Teacher Education, 55(5), 387-393 (Editorial).

Cooper, M., \& Stewart, J. (2009). 'Learning together, shaping tomorrow' New teachers try new ways. Research in Comparative and International Education, 4(1), 111-122.

Darling-Hammond, L. (1996). The quiet revolution: Rethinking teacher education development. Educational Leadership, 53(6), 4-10.

Darling-Hammond, L., Berry, B. T., Haselkorn, D., \& Fideler, E. F. (1999). Teacher recruitment, selection and induction. In L. Darling-Hammond \& G. Sykes (Eds.), Teaching as the learning profession handbook of policy and practice (pp. 183-232). CA: Jossey-Bass.

Feiman-Nemser, S. (2001). Helping novices learn to teach - : lessons from an exemplary support teacher. Journal of Teacher Education, 52(1), 17-30. 
Feiman-Nemser, S. (2003). What new teachers need to learn. Educational Leadership, 60(8), 25-29.

Feiman-Nemser, S., \& Folden, R. (1986). The cultural of teaching. In M.Wittrock (Ed.), Handbook of research on teaching (3rd ed.). (pp.505-526) New York: Macmillan

Guskey, T. (2002). Professional development and teacher change. Teachers and teaching: theory and practice, (8), 381-391.

Hargreaves, A. (2003). Teaching in the knowledge society: Education in the age of insecurity. Philadelphia: Open University Press.

Hargreaves, A., \& Fullan, M. (2000). Mentoring in the new millennium. Theory into Practice, $39,50-56$.

He, Y. (2009). Strength- based mentoring in preservice teacher education: a literature review. Mentoring \& Tutoring: Partnership in Learning, 17(3), 263-275. http://dx.doi.org/10.1080/ 13611260903050205

Hicks, J. (1997). The promise of community in professional development ERIC Document Reproduction Services No. ED 412194.

Hobson, A. J., Ashby, P., Malderez, A., \& Tomlinson, P. D. (2009). Mentoring beginning teachers: What we know and what we don' t. Teaching and Teacher Education, 25(1), 207-216.

Kardos, S., Moore-Johnson, S., Peske, H., Kauffman, D., \& Liu, E. (2001). Counting on colleagues: New teachers encounter the professional cultures of their schools. Educational Administration Quarterly, 37(2), 250-290.

Lincoln, Y., \& Guba, E. (2000). Paradigmatic controversies, contradictions and emerging influences. In N. Denzin \& Y. Lincoln (Eds.), Handbook of qualitative research (2nd ed., pp. 163-188). California: Sage Publications.

Lopez-Real, R., \& Kwan, T. (2005). Mentors' perceptions of their roles in mentoring student teachers, Asia-Pacific Journal of Teacher Education, 33(3), 275-287.

Merriam, S. (1998). Qualitative research and case study applications in education. San Francisco, CA. Jossey-Bass Publishers.

Mulholland, J., \& Wallace, J. (2001). Teacher induction and elementary science teaching: Enhancing self-efficacy. Teaching and Teacher Education, 17, 243-261

New Zealand Teachers Council (2009). Draft Guidelines for Induction and Mentoring programmes and for mentor teacher development in Aotearoa New Zealand. Retrieved on August 14th, 2010, from http://www.teacherscouncil.govt.nz/policy.projects1.stm

New Zealand Teachers Council (2011). Guidelines for Induction and Mentoring and mentor teachers. Retrieved on August 14th, 2010, from http://www.teacherscouncil.govt.nz/content/ guidelines-induction-and-mentoring-and-mentor-teachers-2011-englishpdf 


\section{Macrothink}

Journal of Education and Training

ISSN 2330-9709

2016, Vol. 3, No. 1

Norman, P. J., \& Feiman-Nemser, S. (2005). Mind activity in teaching and mentoring. Teacher and Teacher Education, 21, 679-697.

OECD. (2005). Teachers matter: Attracting, developing and retaining effective teachers. Paris: Author.

Olesen, V. (2000). Feminism and qualitative research at and into the new millennium. In D. K. Denzin \& Y. S. Lincoln (Eds.), Handbook of qualitative research (pp. 215-255.). CA: Sage.

Portner, H. (Ed.) (2005). Teacher mentoring and induction - The state of the art and beyond. CA: Corwin Press.

Thomas, G., Wineburg, S., Grossman, P., Hyhre, O. \& Woolworth, S. (1998). In the company of colleagues: An interim report of the development of community teacher learners. Teaching and Teacher Education, 14(1), 21-32.

Timperley, H. (2008). Teacher professional learning and development. In J. Brophy (Ed.), Educational Practices Series- 18. International Academy of Education and International Bureau of Education: Brussels

Zachary, L. (2000). The mentor's guide: Facilitating effective learning relationships. San Francisco, CA: Jossey-Bass.

\section{Copyright Disclaimer}

Copyright reserved by the author(s).

This article is an open-access article distributed under the terms and conditions of the Creative Commons Attribution license (http://creativecommons.org/licenses/by/3.0/). 